\title{
The Internal Weather of the Sea and Its Influences on Ocean Biogeochemistry
}

\author{
Dennis J. McGillicuddy, Jr. \\ Woods Hole Oceanographic Institution. Woods Hole, Massachusetts USA
}

\section{Introduction}

Interconnections between the physical, biological and chemical processes that regulate carbon cycling in the ocean span a tremendous range of space and time scales. For example, regional to global-scale variations in the biogeochemical constituents of the water column are closely linked with the general circulation of the ocean. At finer scales, such relationships are just as striking, if not more so. A particularly strong manifestation of these linkages occurs at the oceanic mesoscale, sometimes referred to as the "internal weather of the sea." Highly energetic currents, fronts and eddies are ubiquitous features of ocean circulation, with characteristic spatial scales of $10-100 \mathrm{~km}$ and temporal scales of weeks to months. Their space scales are thus smaller and time scales longer than their counterparts in atmospheric weather, but the dynamics of the two systems are in many ways analogous. Both are characterized by large-amplitude departures from mean conditions on relatively small spatial scales, over relatively short periods of time.

Mesoscale phenomena include a diverse set of physical, chemical and biological interactions that influence the distribution and variability of the biogeochemical constituents of the water column. Complex yet highly organized flows continually deform and rearrange the hydrographic structure of the near-surface waters in which plankton reside. These motions affect biogeochemical cycling in two major ways: they alter distributions via the movement of water masses, and they modulate the rates of chemical and biological processes. Common manifestations of the second factor are associated with vertical transport, which can affect the availability of both nutrients and light to phytoplankton and therefore the rate of primary production. The dynamics of mesoscale and submesoscale flows are replete with mechanisms that can produce vertical motions, thereby modulating the efficacy of the biological pump.

In essence, there are two aspects of mesoscale physical-biogeochemical coupling that have major implications for the study of global ocean fluxes. First, unless observations are specifically designed to deal with mesoscale variability, spatial variations propagating through an area can be mistaken for temporal variability in that area. Second, mesoscale dynamic processes themselves can drive significant fluxes that affect local, regional and basin-scale biogeochemical budgets. Examples of both issues will be highlighted in the following brief overview of the U.S. Joint Global Ocean Flux Study (JGOFS) process studies and timeseries programs.

\section{The North Atlantic Bloom Experiment}

The spring bloom in the North Atlantic is one of the most salient seasonal events that affect the global distribution of surface ocean phytoplankton biomass (Figure 1). The basic mechanism controlling this basinscale phenomenon was established by Harald Sverdrup, Gordon Riley and others in the first half of the $20^{\text {th }}$ century. Vigorous winter mixing sets the stage by bringing nutrient-rich deep water into the surface layer. As the mixed layer shoals with the onset of stratification in the spring, the abundance of both light and nutrients stimulates a massive proliferation of phytoplankton. The international North Atlantic Bloom Experiment (NABE), carried out in 1989 as a pilot study for JGOFS, was designed to quantify the fluxes of carbon associated with this annual event and to assess its effectiveness in fueling the biological pump.

JGOFS investigators observed dynamics of the bloom that were generally consistent with the Sverdrup model; the onset of stratification clearly led to a phytoplankton bloom. However, the presence of mesoscale variability complicated interpretation of the measurements in a number of ways. The field of eddies around the sampling site at $47^{\circ} \mathrm{N}, 20^{\circ} \mathrm{W}$ was mapped in real time during the study. Three cyclonic eddy features (referred to as "big," "standard" and "small") were identified with a combination of satellite altimetry and hydrographic observations (Figure 2a). Significant variability in chlorophyll fluorescence associated with these features was evident in Airborne Oceanographic LIDAR surveys of the region. The vertical structure of these cyclones is such that isopycnal surfaces in their 


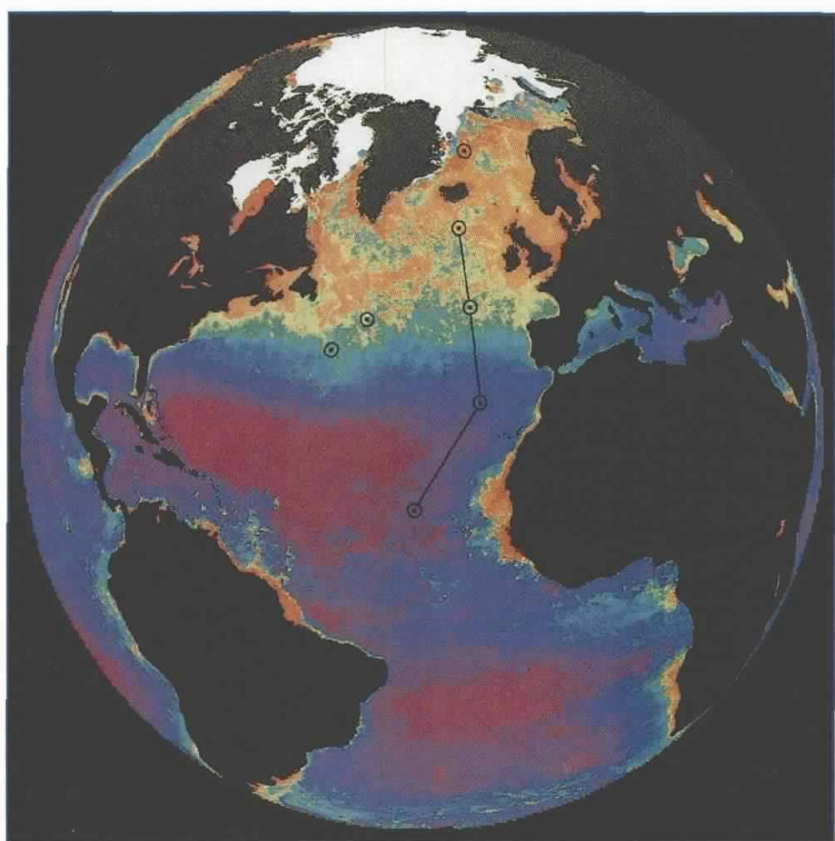

Figure 1. Composite of April-June period for 1979-1986 from the NIMBUS-7 Coastal Zone Color Scanner data showing phytoplankton pigment in the surface ocean. Purple represents lowest pigment levels $\left(<0.1 \mathrm{mg} \mathrm{m}^{-3}\right.$ ), and red represents the highest (>3 $\mathrm{mg}$ $\left.m^{-3}\right)$. Areas of the most intensive studies during the 1989 North Atlantic Bloom experiment are indicated by circles; high-resolution transect work was undertaken along the line roughly following the $20^{\circ} \mathrm{W}$ meridian. (Image by Gene Feldman, NASA Goddard Space Flight Center.)

interiors are domed upward in the water column. Therefore near-surface waters in these features tend to be colder, denser and richer in nutrients than the surrounding ocean.

NABE investigators sampled a mixture of water masses from the mesoscale environment during two time-series studies. Starting near $47^{\circ} \mathrm{N}, 20^{\circ} \mathrm{W}$, the first set of time-series measurements began outside the small eddy and finished inside it two weeks later. The second set of time-series measurements, made over a period of 10 days, were entirely inside the small eddy. What are the ramifications of starting a series of measurements outside the eddy and finishing it inside? Spatial variability can be mistaken for temporal variability; moving from outside to inside causes an apparent sink of heat and source of nitrate in the observations.

This effect can be quantified with the help of a three-dimensional coupled physical-biogeochemical model. For example, sampling simulated mixed-layer nitrate fields in space and time along the first timeseries cruise track (Figure $2 \mathrm{~b} \& \mathrm{c}$ ) produces results (black line) that match the data (green squares). For comparison, the red and blue lines in Figure 2c show the results of one-dimensional simulations at the center and outside of the eddy respectively. Attributing spatial variability in the data to changes over time can significantly affect conclusions regarding the functioning of the system. Moving from outside to inside the eddy results in underestimation of biological utilization related to the apparent source of nitrate. This causes the ratio of new to total production (f-ratio) computed from measurements of primary production and changes in nutrient inventories during the first set of time-series measurements (days 115-128) to be almost a factor of two lower (0.37) than that computed from samples taken from a single water mass (0.64) in the numerical model (Figure 2d).

Although the predominant influence of eddies on the bloom itself appears to be the heterogeneity they bring to the initial conditions for the event, their effect may be even more dramatic after the bloom. Although few NABE samples were taken during the post-bloom period at $47^{\circ} \mathrm{N}$, model simulations indicate that threedimensional dynamic effects associated with interactions among eddies are responsible for most of the new production after the bloom. According to the model, the three cyclonic eddies in the area evolved and interacted very strongly during the two months following the bloom. Simulations indicate that intense vertical motions associated with these interactions cause significant fluxes of nutrients into the euphotic zone. The upwelling caused by eddy interactions substantially increases simulated plant and animal production for periods of weeks. Whether by supplying heterogeneity to the initial conditions of the bloom or through dynamic effects during the post-bloom period, eddies appear to exert a significant influence on the export of biogenic material from the euphotic zone in the North Atlantic sampled during NABE. For example, Newton et al. (1994) document strong mesoscale variability in particle flux to the deep sea in this region. Nonetheless, details of the mechanistic linkage between eddy-driven processes and export to the deep ocean remain largely unknown.

\section{The Equatorial Pacific Process Study}

The equatorial Pacific is home to some of the most striking regional-scale structure and low-frequency variability in carbon cycling anywhere in the world ocean (Murray et al., 1994). Wind-driven upwelling at the equator brings deep water rich in dissolved inorganic carbon to the surface, the source of roughly $1.0 \mathrm{Gt}$ $\mathrm{C} \mathrm{yr}^{-1}$ ( $1 \mathrm{Gt}=10^{9}$ tonnes) that is released into the atmosphere as carbon dioxide $\left(\mathrm{CO}_{2}\right)$. Outgassing in this region, the largest natural net source of $\mathrm{CO}_{2}$ to the atmosphere, is subject to large fluctuations associated with El Niño-Southern Oscillation (ENSO) cycles. For example, deepening of the thermocline during 1991-1992 El Niño conditions appears to have reduced the outgassing of $\mathrm{CO}_{2}$ to $0.3 \mathrm{Gt} \mathrm{C} \mathrm{yr}^{-1}$, roughly one third of its mean value.

Upwelling at the equator also transports large 
(a)

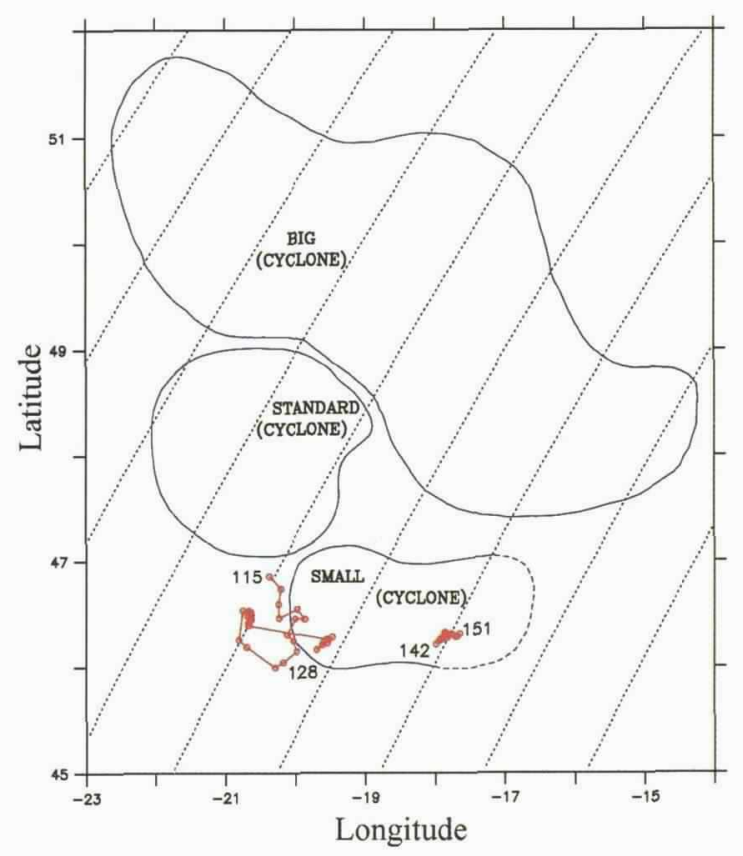

(c)

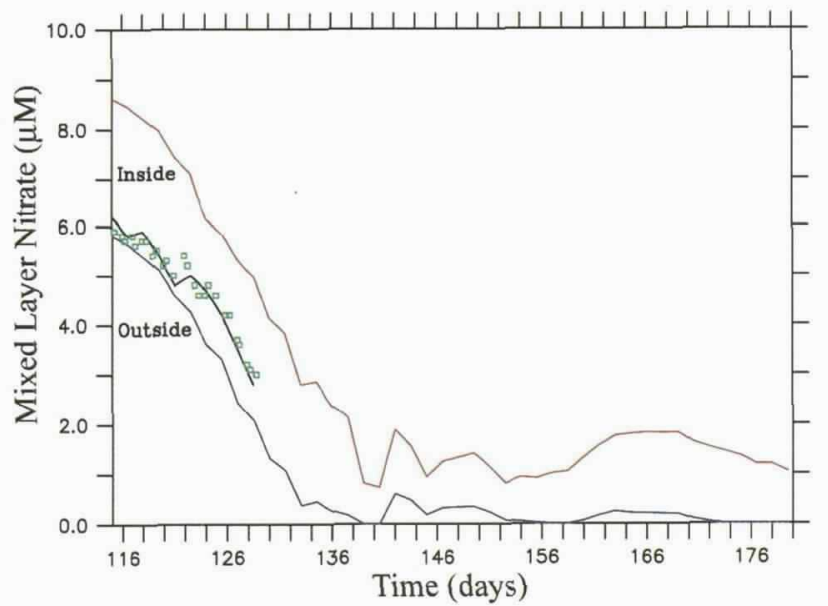

(b)

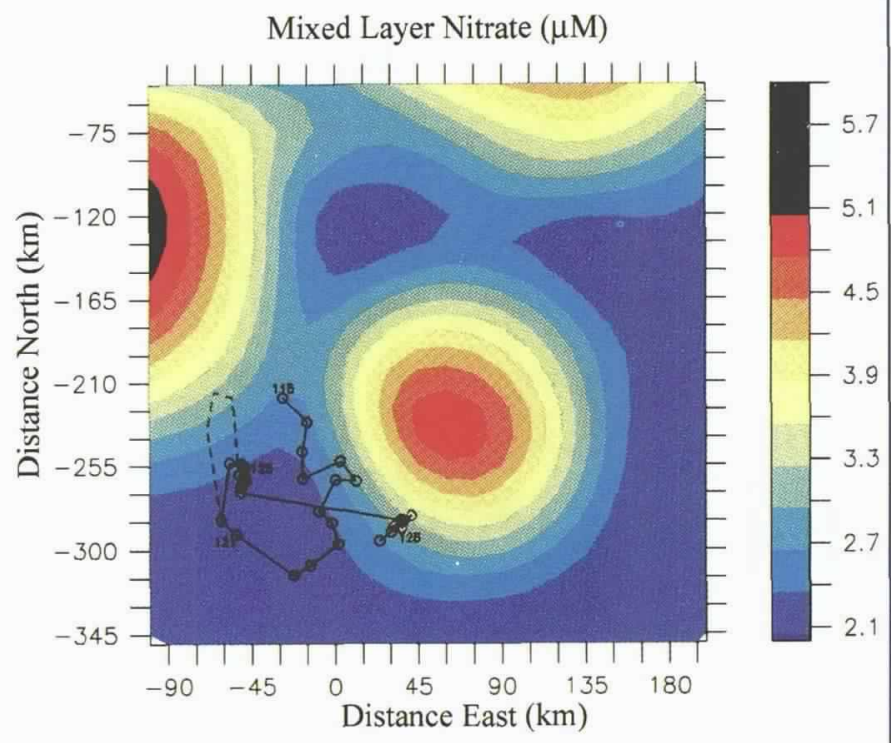

(d)

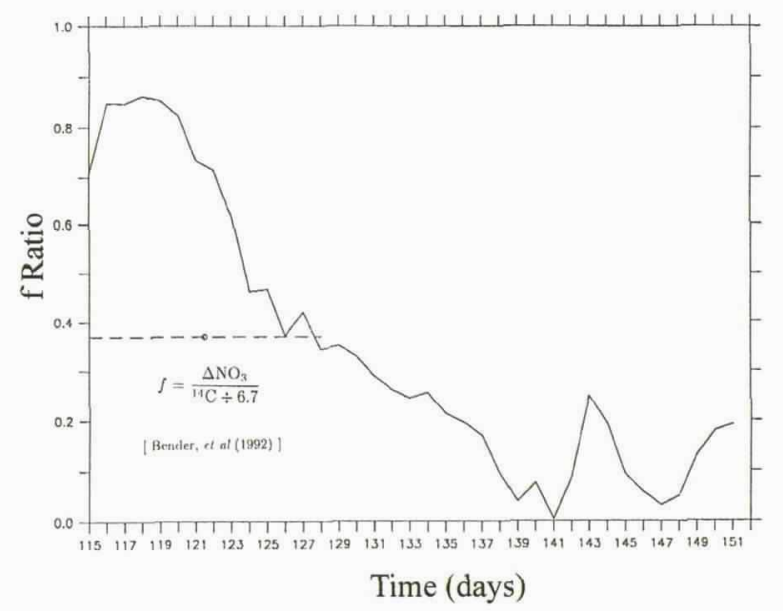

Figure 2. a) Map of a mesoscale eddy field around $47^{\circ} \mathrm{N}, 20^{\circ} \mathrm{W}$ for May 8-24, 1989. Ground tracks of GEOSAT altimetric data used in the analysis are indicated by dotted lines. Two U.S. JGOFS time-series cruise tracks are shown in red. Year days are indicated at the beginning and end of each time-series track. $b$ ) Track of the first time-series cruise superimposed on a field of mixed-layer nitrate simulated with a three-dimensional coupled physical-biogeochemical model. c) Mixed-layer nitrate concentrations in mmol $\mathrm{N} \mathrm{m}^{-3}$ (green squares) and values extracted from the coupled model along the cruise track (solid black line). Red and blue lines indicate the model solutions for inside and outside the eddy respectively. $d$ ) Simulated time-series record of depth-integrated f-ratio outside the "standard" eddy (black line); an observational estimate of the f-ratio during this time period (from Bender et al., 1992) is indicated with an open circle. The dashed line indicates the temporal extent of the data used to compute this average value. Panel a adapted from Robinson et al., 1993; panels $b, c$ and $d$ adapted from McGillicuddy et al., 1995. 
quantities of inorganic nutrients into surface waters, fueling new production of approximately $1.0 \mathrm{Gt} \mathrm{C} \mathrm{yr}{ }^{-1}$, a significant fraction of the global total. The fact that the upwelled nutrients are not fully utilized by phytoplankton leads to the enigmatic persistence of the highnutrient, low-chlorophyll (HNLC) conditions characteristic of this region. A variety of mechanisms have been proposed to explain this phenomenon, from "bottom-up" regulation through the supply of micronutrients such as iron to "top-down" control through zooplankton grazing. Idealized box-models that explicitly represent the joint effects of bottom-up control on large phytoplankton (silica limitation on diatoms) and topdown control on small phytoplankton (microzooplankton grazing on picoplankton) predict new and export production comparable to measured values (Dugdale and Wilkerson, 1998). Various aspects of this diverse set of controls have been incorporated into threedimensional circulation models that show some success in simulating the large-scale mean characteristics of the nutrient and chlorophyll distributions of the region (Figure 3 ).

What are the detailed processes responsible for regulating biogeochemical cycling in the equatorial Pacific? Thirteen months ${ }^{\prime}$ worth of continuous timeseries observations from moored bio-optical instruments deployed during the U.S. JGOFS Equatorial Pacific Process Study (EqPac) in the early 1990s documented vigorous variability on time scales ranging from days to seasons (see Dickey, this issue). Much of the energy in higher-frequency fluctuations observed in such fixed-point records is associated with wavelike disturbances propagating through the region, including Kelvin waves and tropical instability waves (TIWs).

A spectacular manifestation of the effect of a TIW on surface ocean physical and biogeochemical properties was observed during an EqPac cruise in August 1992 (Figure 4). Although the characteristic wavelength of such features is quite large (on the order of $1000 \mathrm{~km}$ ), the frontal boundary along the leading edge can be extraordinarily sharp (less than $1 \mathrm{~km}$ ). The front associated with this TIW produced a "line in the sea" visible to astronauts flying overhead on the space shuttle Atlantis as well as to those on board ship (Figure 4a).

Shipboard observations revealed an extraordinary abundance of the buoyant diatom Rhizosolenia castracanei. Concentrations of this organism were sufficient to discolor the water, giving it a brown appearance on the warm side of the front. A few meters away on the cold side of the front, surface waters were a more characteristic blue (Figure $4 \mathrm{~b}$ ). Analysis of elemental budgets in the observed velocity field (Figure 4c) suggests that the very high diatom concentrations observed at the front were predominantly a result of accumulation rather than local photosynthesis. Convergence at the front, in concert with the upward motion of the buoyant organisms through the water, concentrated them in regions of strongest downwelling.

The extraordinary aggregation of diatoms at the line in the sea appears to be only the surface manifestation of the dramatic effect of the TIW on upper-ocean ecosystem structure. Shipboard measurements show that total chlorophyll increased by about a factor of two as such waves passed. Moreover, the diatom contribution to total chlorophyll increased three- to four-fold (Bidigare and Ondrusek, 1996). EqPac investigators found that the periods of strongest TIW activity coincided with peaks in the flux of organic carbon and biogenic silica to the deep sea (Honjo et al., 1995). However, the peaks in these fluxes did not occur near the equator where the line in the sea was observed, but farther north and south at $5^{\circ} \mathrm{N}$, $2^{\circ} \mathrm{S}$ and $5^{\circ} \mathrm{S}$. Although vigorous meridional velocities on the order of $100 \mathrm{~cm} \mathrm{~s}^{-1}$ associated with TIWs are sufficient to explain this poleward displacement by horizontal advection, existing data are not sufficient to confirm or reject this hypothesis.

Mechanistic links between the activity of various types of waves and upper ocean biogeochemical response have been investigated in the context of numerical models. For example, Friedrichs and Hofmann (2001) explicitly included the effects of waveinduced motions in a one-dimensional coupled physical-biological model, using vertical velocities diagnosed from measurements made by instruments on the Tropical Atmosphere Ocean (TAO) mooring array. Their simulations suggest that the increase in chlorophyll and change in species composition associated with TIWs observed during EqPac cruises resulted from the combination of two factors: enhanced growth stimulated by the vertical advection of iron and accumulation of buoyant diatoms in the convergence at the leading edge of the front.

Friedrichs and Hofmann also found that the largeamplitude equatorially-trapped internal gravity waves characteristic of this region can also stimulate phytoplankton growth locally through the vertical advection of iron into the euphotic zone. Because the time scale for iron utilization by rapidly growing picoplankton is short compared to the period of these internal gravity waves (6-8 days), this mechanism can result in a large net flux of iron into the euphotic zone-perhaps $30 \%$ or more of the mean flux resulting from wind-driven upwelling alone. However, detailed partitioning of the fluxes among all of the processes active in the equatorial Pacific is made difficult by the convolution of variability present in the observations; relevant time scales range from interannual (El Niño) to weeks (TIWs) to days (internal gravity waves).

\section{The Arabian Sea Process Study}

The Arabian Sea is a highly productive region with sediments that are rich in organic carbon. It is one of the few areas of the world ocean with a mid-depth oxygen minimum zone, which contributes to its distinct biogeochemical character. The region is also subject to a regular oscillation in powerful monsoonal winds, which have a dramatic effect on the structure of the upper water column. The 1994-1996 Arabian Sea Process 

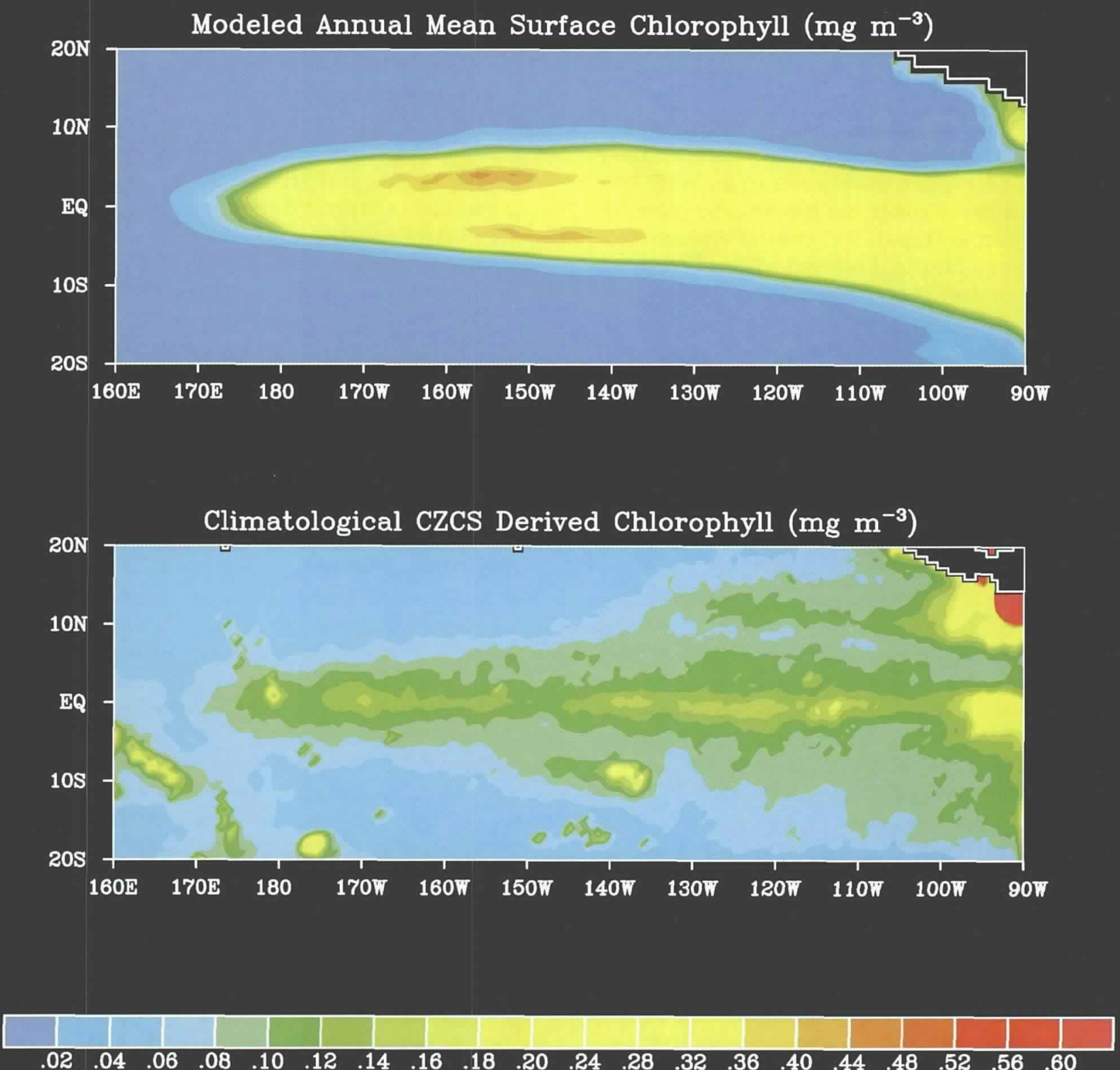

Figure 3. Comparison of modeled annual mean surface chlorophyll from Chai et al., 1996 (top panel) with chlorophyll derived from Coastal Zone Color Scanner (CZCS) data (bottom panel). Although the overall simulated pattern agrees with the CZCS data with respect to the positions of the maximum zonal and meridional gradients, there are several notable discrepancies. First, the modeled chlorophyll along the equator is about a factor of two higher than the CZCS estimates. In-situ chlorophyll measurements reveal that the mean surface chlorophyll is generally closer to the simulated values, suggesting that the CZCS underestimated chlorophyll concentrations in the equatorial Pacific. Second, the modeled surface chlorophyll maxima occur at $3^{\circ} \mathrm{N}$ and $3^{\circ} \mathrm{S}$, whereas the CZCS data show a maximum right on the equator. In-situ observations appear to be more consistent with the simulation (Bidigare and Ondrusek, 1996). The discrepancy may be a result of temporal and spatial averaging of the CZCS data.

Study (ASPS) provided an opportunity for detailed investigation of biogeochemical responses to this strong atmospheric forcing.

The processes that regulate the biogeochemical effects of monsoonal forcing are complex. During the summer months, the warm, moist air of the southwest monsoon flows in a strong jet along the western portion of the basin (Figure 5a). This results in vertical motion 
(a)

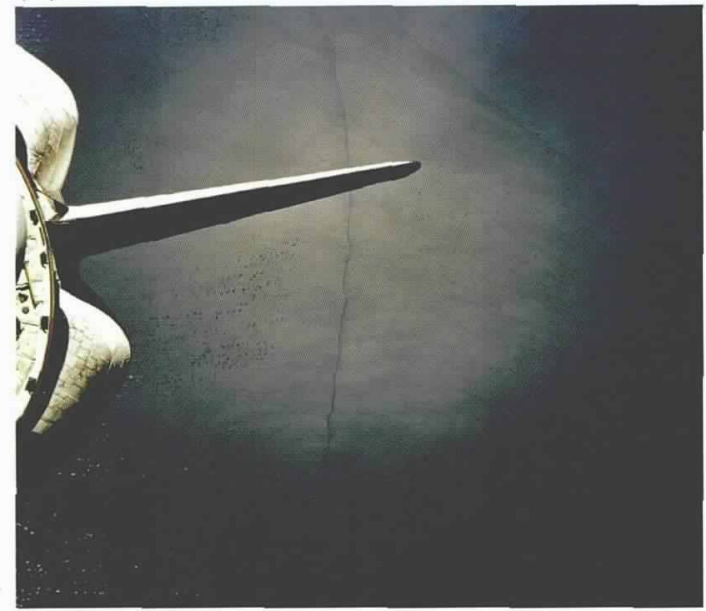

(b)

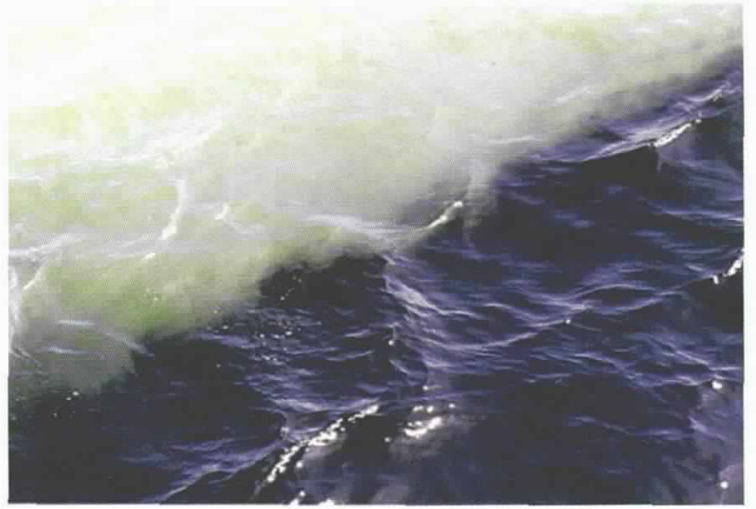

(c)

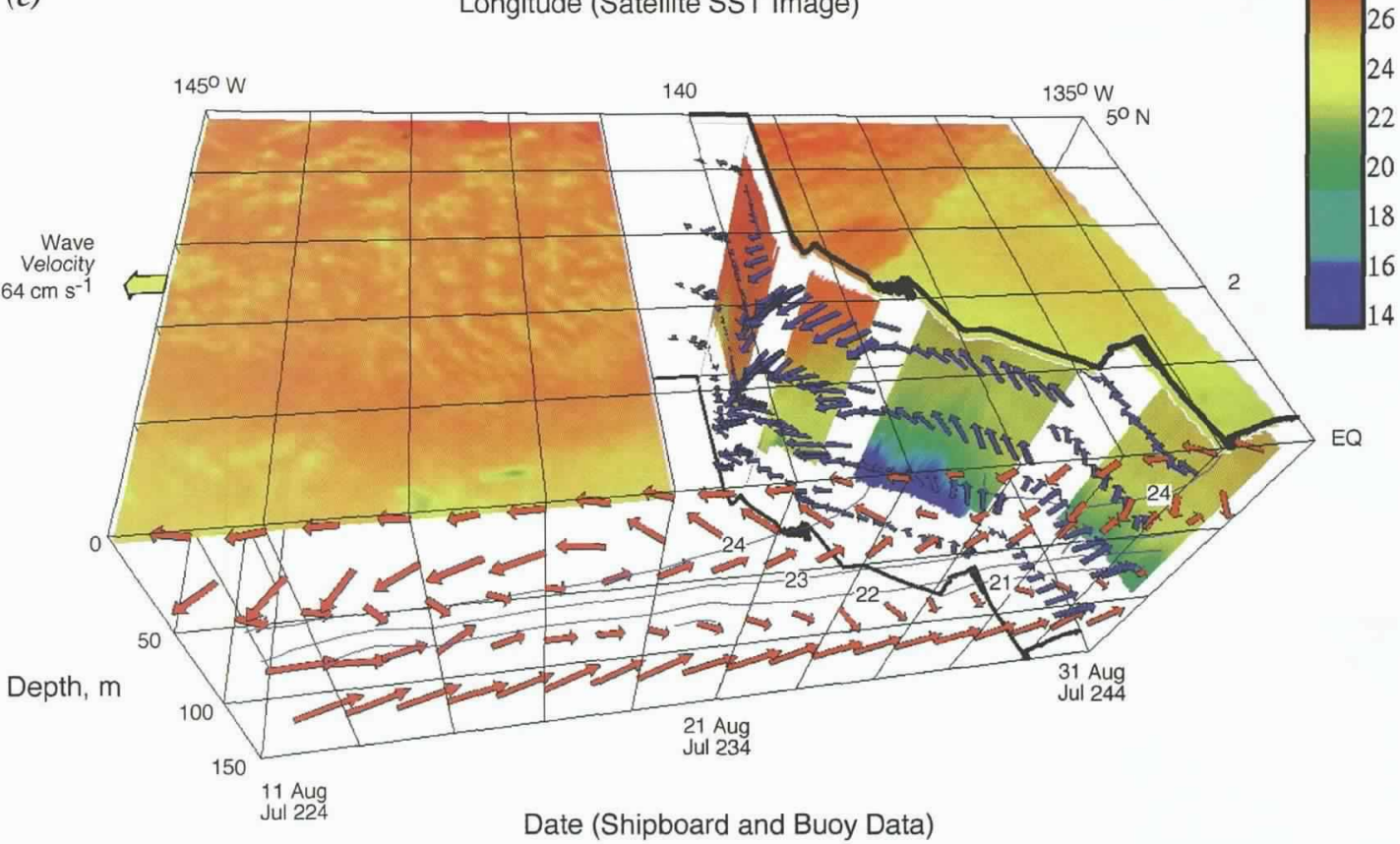

Figure 4. a) View from the space shuttle Atlantis. $b$ ) Photograph from the deck of R/V Thomas G. Thompson showing the sharp boundary at which surface waters were discolored by high concentrations of Rhizosolenia castracanei. $c$ ) Physical structure of the tropical instability wave. A sea-surface temperature (SST) swath from the NOAA AVHRR satellite is cut away to reveal subsurface detail from shipboard and moored observations. The satellite image was taken on Aug. 21, when the ship was at $5^{\circ} \mathrm{N}$. To correct for the westward propagation of the wave, the shipboard and moored data have been transposed to the east at a rate of $0.5^{\circ}$ per day. The convergent front is evident in the diagonal line in SST, reaching from about $140^{\circ} \mathrm{W}$ at the equator to $5^{\circ} \mathrm{N}, 135^{\circ} \mathrm{W}$. Subsurface temperatures from the surface to approximately $100 \mathrm{~m}$ depth were observed with an undulating oceanographic recorder. Horizontal velocity estimates come from shipboard and moored acoustic Doppler current profiler (ADCP) data. A vector length of one degree (squares on surface) corresponds to a velocity of $333 \mathrm{~cm} \mathrm{~s}^{-1}$. North of the front, the water flows parallel to the front towards the southwest. Just south of the front, the water flows into the front, subducting to the northwest. Near the equator, surface water flows to the west and the equatorial undercurrent to the east. Panels $a$ and $b$ are from Yoder et al., 1994; panel $c$ is from Archer et al., 1997. 


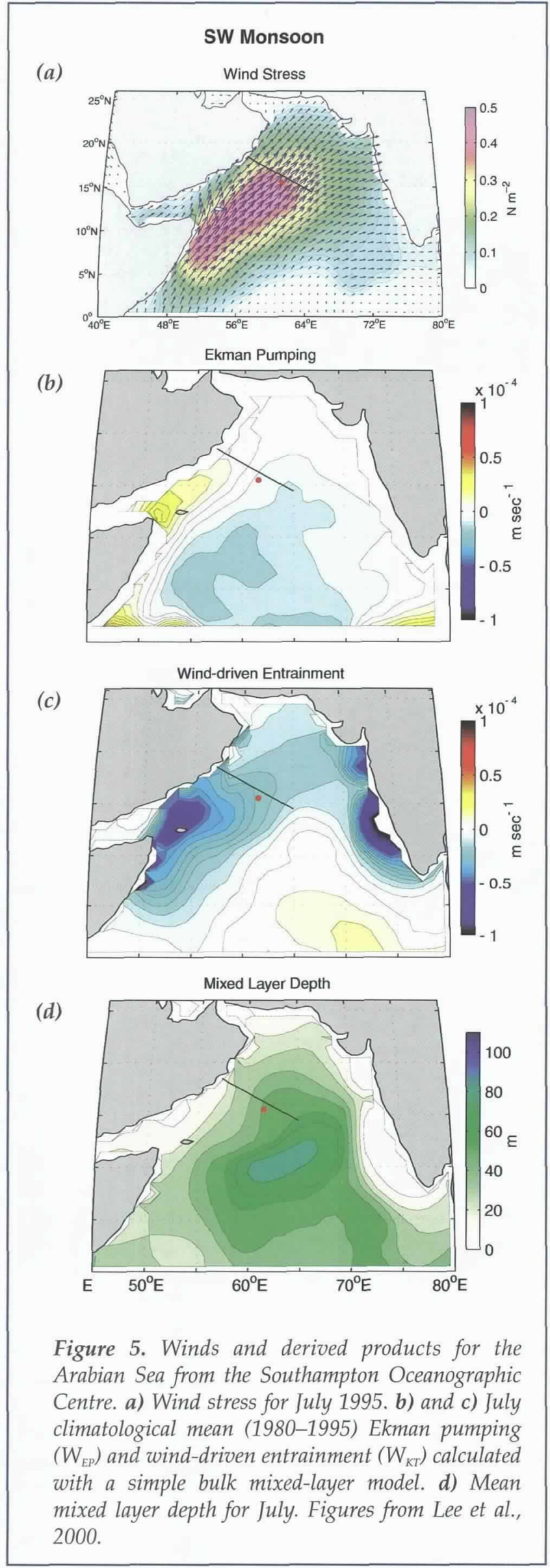

associated with wind-stress curl anomalies on either side of the jet (Figure 5b): downwelling along its southeastern flank and upwelling on its northwestern side. This particular wind-driven upwelling phenomenon occurs well offshore from the continental shelf. The winds themselves also enhance vertical mixing through direct input of turbulent energy (Figure 5c). The combination of these upwelling/downwelling phenomena and wind-driven turbulence generate significant spatial gradients in the depth of mixing (Figure $5 \mathrm{~d}$ ) and therefore entrainment of nutrients and other elements from below the mixed layer.

This analysis demonstrates that a complex mixture of open-ocean processes affect vertical exchanges in the Arabian Sea. However, one of the most striking findings of the ASPS was the degree to which coastal processes and associated filaments and eddies could contribute to biogeochemical cycling in the open ocean (Smith, 2001). The southwest monsoon wind pattern is favorable for coastal upwelling along the western edge of the basin. Just as in other regions of coastal upwelling, mesoscale filaments can transport upwelled waters large distances from the coast.

Detailed SeaSoar surveys, satellite data and acoustic Doppler current profiler (ADCP) observations clearly documented the penetration of an upwelling-derived coastal filament well into the interior of the basin during the summer of 1995 (Figure 6). The biogeochemical signature of this filament was unmistakable during ASPS cruises. One encounter with this feature some $723 \mathrm{~km}$ off the coast in July revealed the highest biomass and productivity observed during the late southwest monsoon period (Barber et al., 2001). Pigment analysis showed a dramatic shift in the phytoplankton community, with diatoms constituting a large fraction of the total chlorophyll (Latasa and Bidigare, 1998). Observed depletion of silicic acid relative to nitrate is consistent with a diatom bloom within the filament. Time-series measurements of biogenic silica in deep sediment traps suggest that such shifts in species composition appear to be related to large exports of organic carbon in this region, which are clearly affected by coastal filaments (Honjo et al., 1999).

The relative importance of coastal and open-ocean upwelling in supplying the nutrients that drive the Arabian Sea's vigorous biological pump remain uncertain. Observations during ASPS suggested the dominance of coastal upwelling, eddies and filaments during the southwest monsoon and convectively driven mixing during the northeast monsoon (Smith, 2001). Surprisingly, spatially averaged productivity during these two time periods was approximately equal (Barber et al., 2001).

Coastal upwelling filaments were by no means the only type of mesoscale feature observed during the ASPS. Mesoscale eddies were prominent in the velocity field measured by shipboard ADCP (Kim et al., 2001). Eddy events were clearly discernible in moored timeseries measurements of physical and bio-optical vari- 


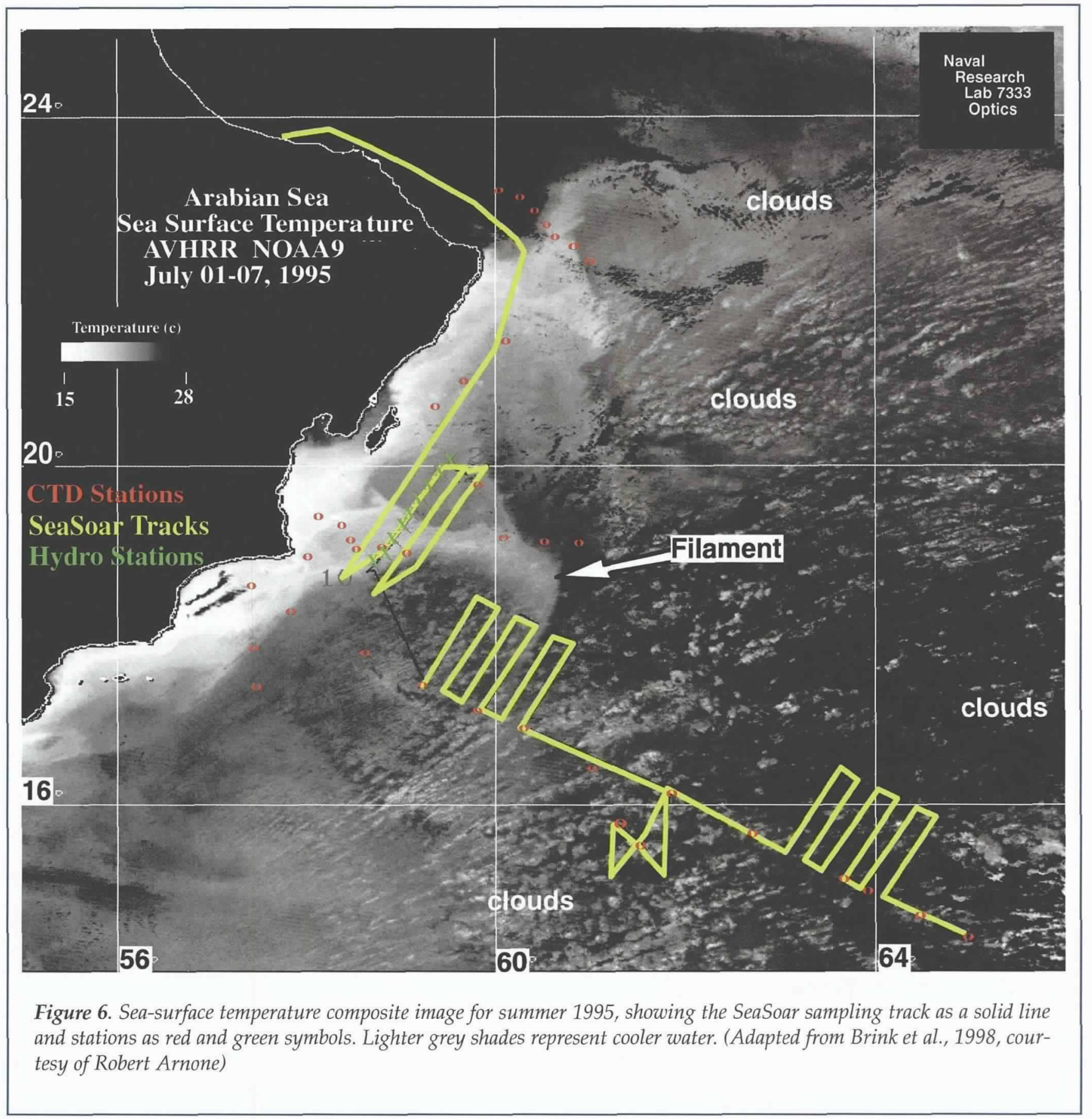

ables as well (see Dickey, this issue). Comparison of deep sediment-trap data with the mooring records suggests that the timing of several, but not all, of the largest export events coincides with the appearance of mesoscale features in the upper ocean (Honjo et al., 1999).

Eddy variability may exert some control on largescale biogeochemical distributions as well. Kim et al. (2001) note that the geographic extent of the mid-depth oxygen minimum zone in the northeast-central portion of the basin coincides with a minimum in eddy kinetic energy observed in the TOPEX/Poseidon altimetric record. Nevertheless, despite this set of intriguing observations, it is still difficult to quantify the integrated effect of mesoscale processes on biogeochemical cycling in the Arabian Sea. Although three-dimensional coupled models of this region are advanced, they have tended to focus on physical-biogeochemical interactions that occur on larger scales. More explicit treatment of the highly energetic mesoscale variability observed during the ASPS will certainly help to quantify the effect of these phenomena on the overall functioning of the system. 


\section{The Antarctic Environment and Southern Ocean Process Study}

The Southern Ocean is the largest HNLC region in the world ocean. Although chlorophyll concentrations are generally low throughout, elevated pigment biomass is found in three different regimes: coastal and continental shelf waters, areas of seasonal sea ice retreat and in the vicinity of major fronts (Figure 7). Despite the relatively low levels of chlorophyll in surface waters, particle fluxes to the ocean interior are high. Organic carbon fluxes measured from the Antarctic Polar Front (APF) southward during the U.S. JGOFS Antarctic Environment and Southern Ocean Process Study (AESOPS) in 1996-98 were approximately twice the ocean-wide average of $1 \mathrm{~g} \mathrm{C} \mathrm{m}^{-2} \mathrm{yr}^{-1}$, and biogenic silica fluxes were among the highest measured in the entire JGOFS program (Honjo et al., 2000). Lithogenic fluxes to the deep sea were among the lowest measured in the open ocean, consistent with low dust input and associated iron limitation of phytoplankton production. It has been suggested that much of the global oceanic uptake of $\mathrm{CO}_{2}$ occurs in the Southern Ocean, and coupled atmosphereocean models indicate that uptake in this region may be very sensitive to climate change (Sarmiento et al., 1998). Thus the need to understand carbon fluxes in this region is particularly compelling (Smith et al., 2000).

AESOPS comprised studies in two different regions: the $\mathrm{APF}$ and the Ross Sea. Mesoscale processes were evident in both areas; Ross Sea processes are described in the accompanying sidebar by Hales et al., and processes in the APF are treated here. Observational approaches to resolving mesoscale fluctuations in the vicinity of the APF took several forms, including an array of bio-optical moorings, clusters of bio-optical drifters and high-resolution SeaSoar surveys (Barth et al., 2001). All three techniques revealed mesoscale and submesoscale variability that would be extremely difficult to resolve using traditional hydrographic measurements.

SeaSoar observations in the APF documented highly organized structure in the chlorophyll field, with a large peak in chlorophyll situated at a meander crest (Figure 8). Analysis of two surveys conducted approximately one week apart demonstrated the persistence of this chlorophyll feature at the meander crest. This finding is particularly intriguing given the fact that advection by a strong, narrow current in the meander displaces water parcels by 100-200 $\mathrm{km}$ over this time interval. Thus it appears that the peak in chlorophyll is a response to an upstream perturbation that persists for time scales of at least one week.

What processes could be responsible for such a perturbation? Woods (1988) suggests that intense vertical motion associated with a meandering front could give rise to mesoscale variations in phytoplankton productivity and biomass. The internal dynamics of mesoscale currents is such that changes in curvature give rise to submesoscale regions of upwelling and downwelling oriented within the crest and trough structure. Thus a fluid parcel moving through the current experiences

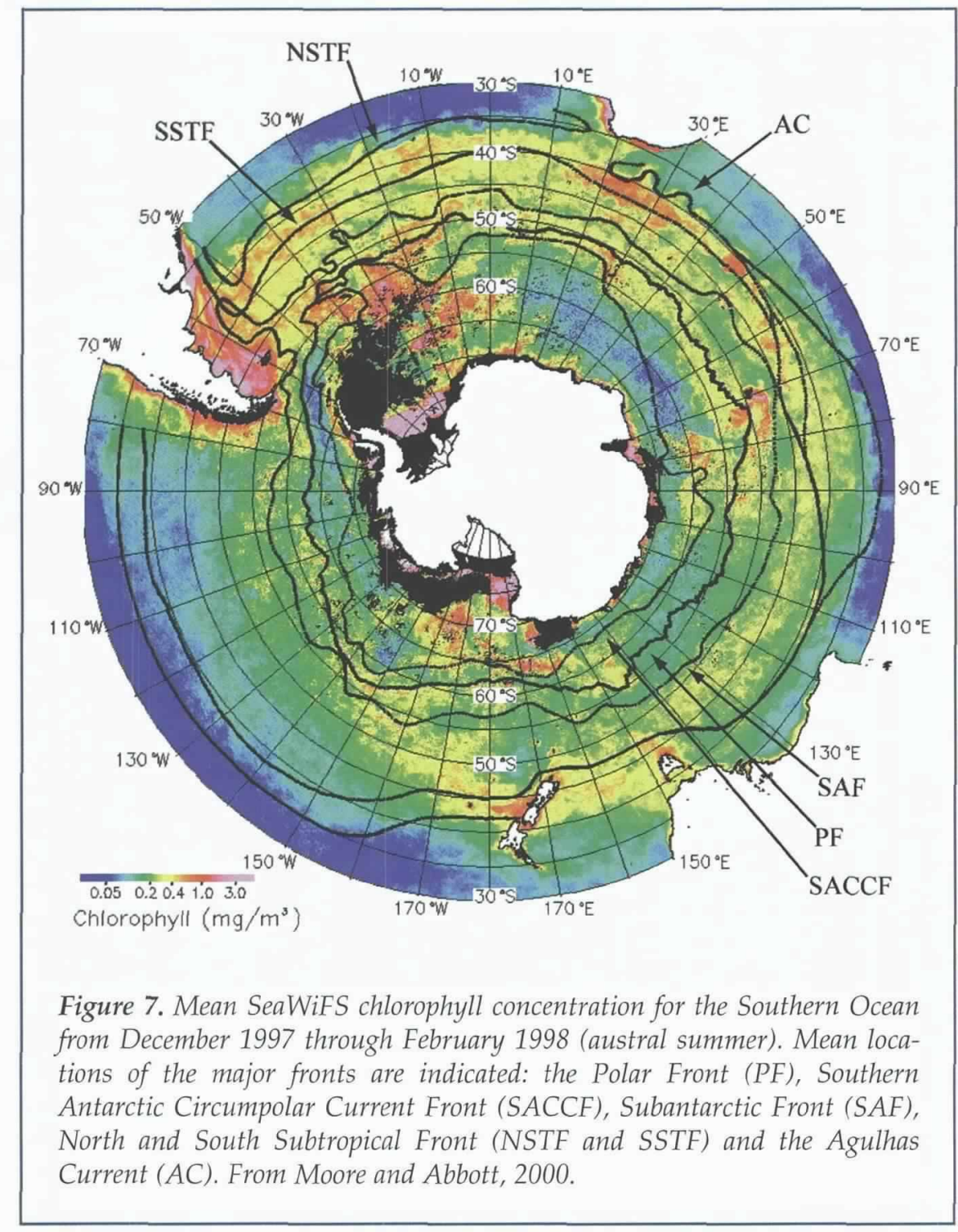


alternating bouts of upwelling and downwelling on a time scale set by its advective characteristics.

Based on growth rate calculations and the observed velocity field, Barth et al. (2001) infer that the observed chlorophyll peak was actually a response to upwelling of nutrients and/or trace metals in the preceding meander, located approximately $200 \mathrm{~km}$ upstream. What is the net effect of these motions on upper ocean biota, and how do they work together to create the elevated levels of biomass at the front that are shown in Figure 7? A complex mixture of horizontal advection, vertical advection and vertical mixing is clearly involved. However, the detailed dynamic balances are yet to be fully understood.

\section{The Time-series Programs}

Interpretation of time-series observations at fixed locations in the ocean is often complicated by the presence of spatial heterogeneity that changes over time. The phenomena to which this statement applies span a tremendous range of spatial and temporal scales, from microscale patchiness to decadal fluctuations in the general circulation. Ultimately, the utility of time-series measurements for understanding oceanic processes depends on our ability to differentiate between spatial and temporal variability.

U.S. JGOFS has produced two of the highest quality biogeochemical time-series programs to date: the Hawaiian Ocean Time-series (HOT) and the Bermuda Atlantic Time-series Study (BATS). Typical sampling intervals of one month resolve the seasonal cycle, and interannual trends are clearly evident (see Karl et al., this issue). Superimposed on these signals are higher frequency variations with amplitudes sometimes comparable to the explicitly resolved time scales. In attempting to develop a mechanistic understanding from the time-series records, it is relevant to inquire about the nature of the unresolved phenomena and their net effect on the overall characteristics of the system.

One aspect of biogeochemical cycling in which mesoscale processes may play a significant role is nutrient supply to the upper ocean. We have known for some time that geochemical estimates of new production in the main subtropical gyres of both the Atlantic and Pacific far surpass levels that can be sustained by traditional mechanisms of nutrient supply (e.g. Jenkins and Goldman, 1985). Several different lines of evidence emerging from both time-series sites now suggest that eddy-induced upwelling may provide a significant fraction of the "missing" nutrients.
Letelier et al. (2000) synthesized a variety of data from the shipboard measurements, moored sensors and satellite-based instruments to describe the passage of a mesoscale feature at the HOT site during the spring of 1997 (Figure 9). That event resulted in a three-fold increase in chlorophyll concentrations in the top $25 \mathrm{~m}$ of the water column and an increase in the inventory of nitrate plus nitrite of more than four orders of magnitude in the top $100 \mathrm{~m}$. In addition, this feature had a dramatic effect on community structure. Pigment analysis suggests that the relative contribution of diatoms to the standing stock of chlorophyll $a$ increased twofold in the interior of the eddy.

Investigators have observed similar events near Bermuda. Comparison of two nutrient profiles, taken one month apart in the summer of 1986 at nearby Station S before BATS began, suggested an eddy-driven nutrient injection event that could account for $20-30 \%$ of the annual new production (Jenkins, 1988). Since that time, the advent of moored biogeochemical measurement systems has provided the opportunity for much higher resolution of such phenomena in a time-series mode.

Data from the Bermuda Testbed Mooring program have revealed a number of mesoscale events at the BATS site (see Dickey, this issue). For example, in July 1995 a nutrient pulse and associated increase in chlorophyll and particulate material was associated with the passage of a mode-water eddy (Figure 10). This feature 


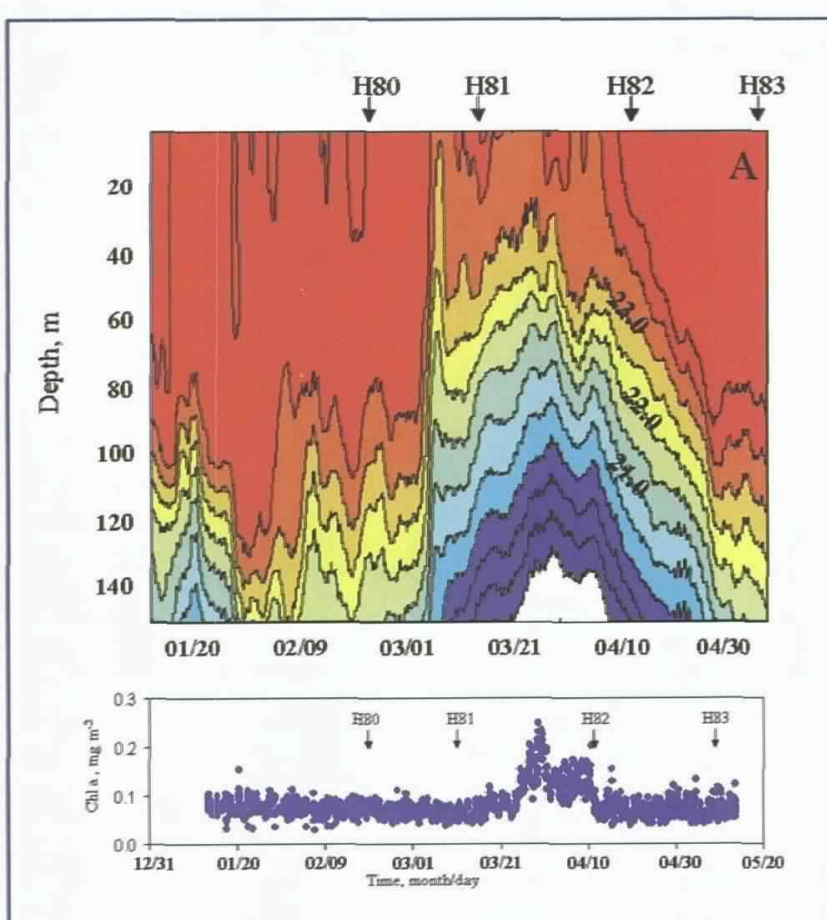

Figure 9. An eddy event recorded in time-series data from the HALE ALOHA mooring: a) Temperature between the surface and $150 \mathrm{~m}$ measured from an array of thermistors $\boldsymbol{b}$ ) Chlorophyll a in the upper $25 \mathrm{~m}$. Note the dramatic shoaling of isotherms and increase in chlorophyll a that takes place in between HOT stations 81 and 82. From Letelier et al., 2000.

was clearly visible as a positive sea-level anomaly in satellite altimetry (Figure 11; also see http:// science.whoi.edu/users/mcgillic/tpd/tpd.html). BATS observations during this period document a depletion in silicic acid together with dramatic changes in pigment composition, suggesting that a bloom of diatoms occurred within the eddy.

Although fixed-point time-series measurements are indispensable, spatial information is essential to put them in context. Mesoscale biogeochemical surveys carried out as part of the BATS validation cruises demonstrate that eddy-induced upward displacement of density surfaces can inject nutrients into the euphotic zone, bringing about the accumulation of biomass in the overlying waters (McGillicuddy et al., 1998). Satellite data show correlated variation in mesoscale ocean color and sea-surface temperature patterns in the Sargasso Sea that is consistent with these results.

Although this diverse set of observations provides a phenomenological basis for description of the effects of mesoscale processes on the biogeochemical properties of ocean systems, models are necessary to get at the statistics. Some evidence suggests that mesoscale eddies supply a significant portion of the annual nutrient budget. Regional numerical simulations indicate that eddy-induced upwelling causes intermittent flux- es of nitrate into the euphotic zone in amounts sufficient to balance the nutrient demand implied by geochemical estimates of new production. Nitrate flux calculations based on satellite altimetry and a statistical model linking sea-level anomalies to subsurface isopycnal displacements provide estimates of a comparable order (Siegel et al., 1999).

\section{Conclusions}

These examples from the U.S. JGOFS field studies demonstrate the striking relationships between physical and biogeochemical properties that occur at the oceanic mesoscale. There are several important ramifications with respect to global ocean fluxes. First, mesoscale motions create spatial heterogeneity that makes discrete measurements difficult to interpret. These difficulties can be overcome by spatio-temporal averaging over a suitably large number of observations. However, practical constraints associated with existing technology generally preclude such an approach in process studies and time-series programs. Thus we are faced with the problem of extracting largescale signals from observations that are strongly affected by the mesoscale environment. Fortunately, remote sensing measurements, advanced in situ measurement techniques and numerical modeling help to diagnose the signature of mesoscale effects in biogeochemical data sets, thereby ameliorating the sampling problem to some degree.

It is also clear that the relevance of mesoscale physical-biogeochemical interactions runs much deeper than the sampling issue. At least for some areas of the world ocean, there is substantial evidence to indicate that eddies play a significant role in driving biogeochemical budgets. Given that mesoscale phenomena are ubiquitous and particularly energetic features of ocean circulation, it is possible that this finding may have general applicability. However, the nature of mesoscale physical-biogeochemical linkages has yet to be elucidated fully. Several examples cited above suggest that mesoscale physical disturbances cause shifts in planktonic species assemblages that then lead to large fluctuations in export. Among these phenomena are tropical instability waves in the equatorial Pacific, coastal filaments in the Arabian Sea and mid-ocean eddies at the HOT and BATS sites. Thus complex and highly nonlinear biological processes may regulate the biogeochemical ramifications of mesoscale perturbations.

How will we make progress on this complex and interdisciplinary problem? Rapidly developing measurement technologies (see Dickey, this issue) are leading to significant advances in our ability to sample biogeochemical quantities on space and time scales previously resolved only for physical properties. Despite these promising developments, it will not be practical to resolve all space and time scales of interest with observations alone; the union between observations and models is critical. Coupled physical-biogeo- 
(a)

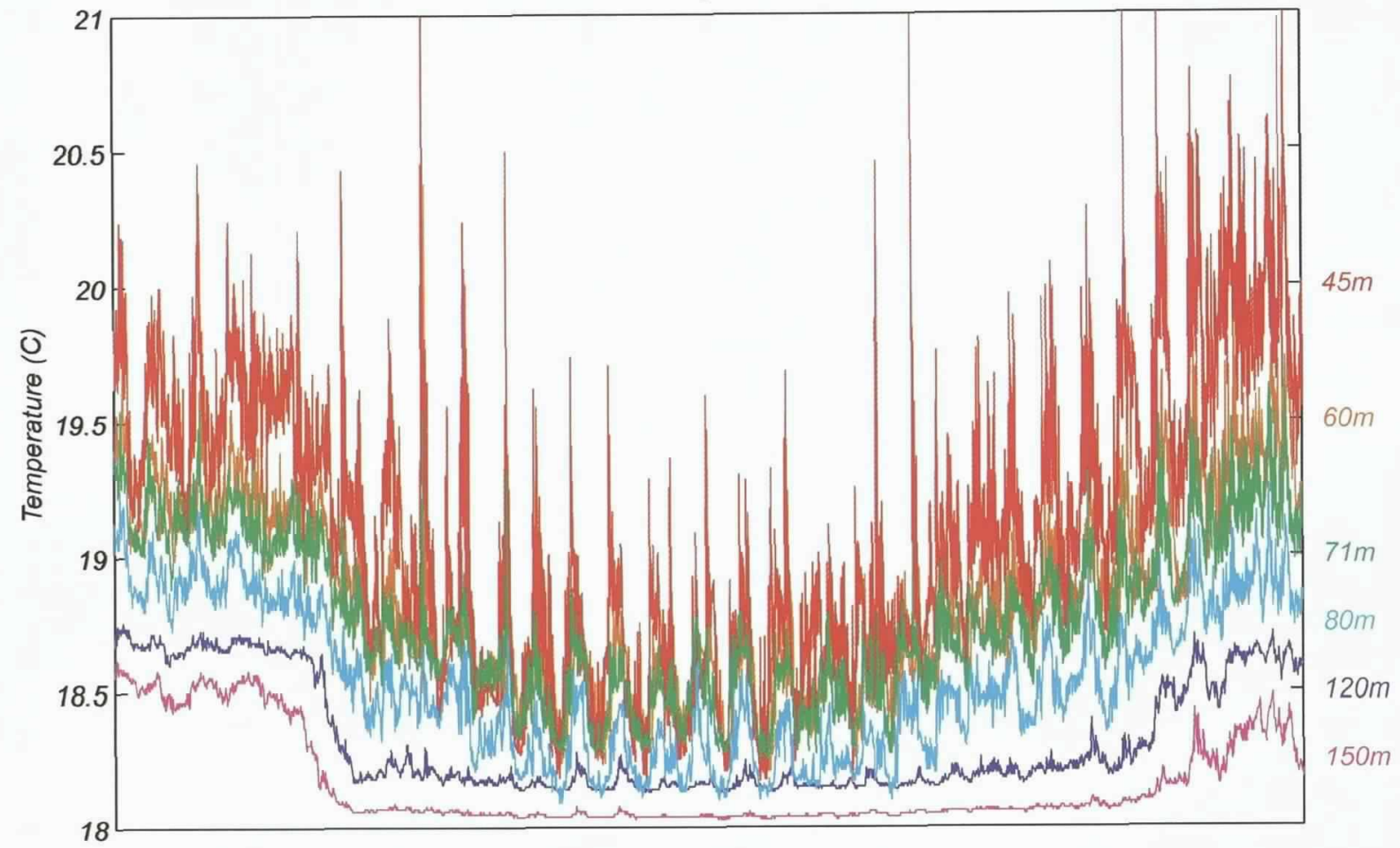

(b)

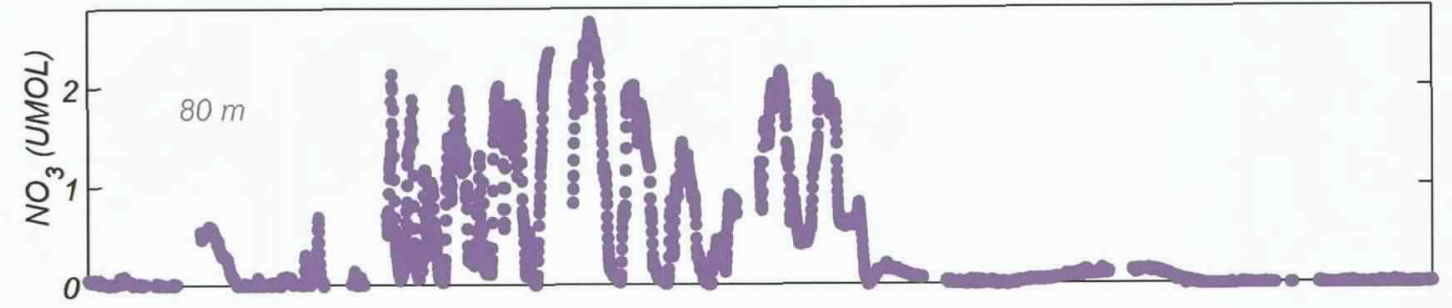

(c)

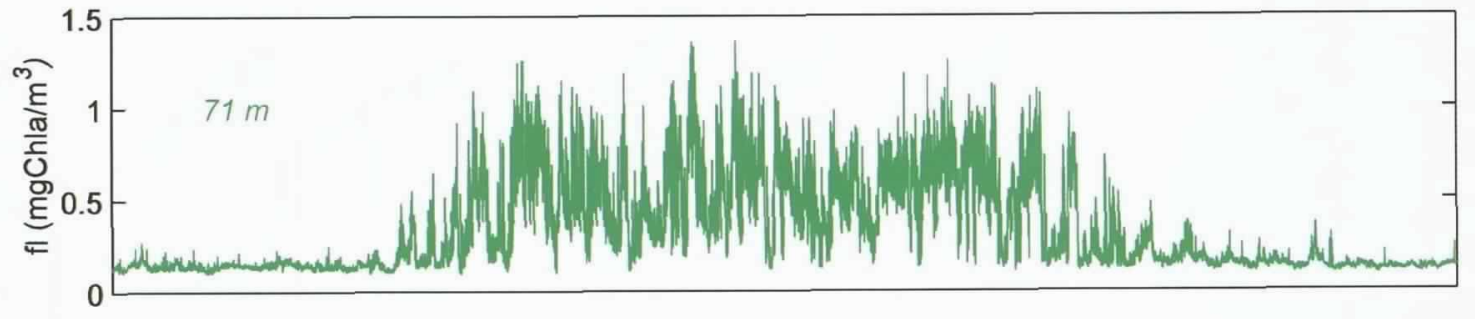

(d)

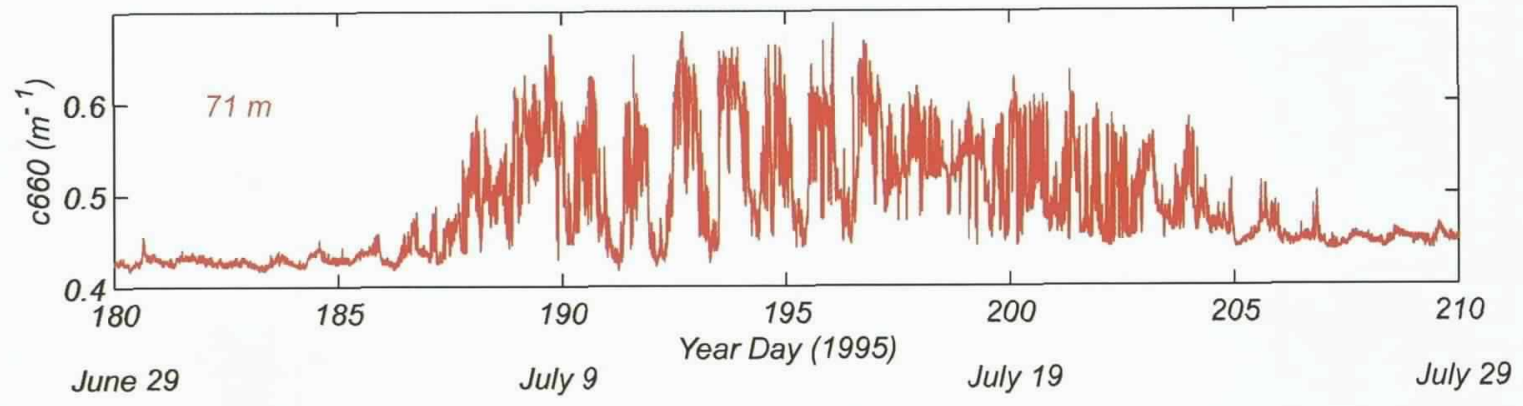

Figure 10. A mode-water eddy passes by the Bermuda Testbed Mooring. Time-series measurements of upper-ocean temperatures between $45 \mathrm{~m}$ and $150 \mathrm{~m}$ reveal a dramatic cooling in the beginning of July 1995 that persists for several weeks (panel a). Large-amplitude increases in both nitrate at $80 \mathrm{~m}$ (panel $\boldsymbol{b}$ ) and chlorophyll a fluorescence at $71 \mathrm{~m}$ (panel c) are associated with the eddy disturbance. The rise in beam attenuation coefficient at $71 \mathrm{~m}$ during this period (panel d) suggests an increase in particulate material. From McNeil et al., 1999. 


\section{small-scale Variability In The Ross Sea}

Burke Hales

Oregon State University

Corvallis, Oregon USA

Colm Sweeney and Taro Takahashi

Lamont-Doherty Earth Observatory

Palisades, New York USA

U.S. JGOFS studies of meso- and sub-mesoscale processes and variability in the Ross Sea were carried out with four oneday deployments of the Lamont Pumping SeaSoar (LPS) from RVIB Nathaniel B. Palmer during November and December 1997. Three of these were conducted along $76.5^{\circ} \mathrm{S}$, and the fourth was a three-dimensional survey of a $60 \mathrm{~km}^{2}$ grid centered on $76.5^{\circ} \mathrm{S}$ between $172^{\circ} \mathrm{E}$ and $174^{\circ} \mathrm{E}$ and selected because of high chlorophyll levels observed by satellite-mounted sensors and relayed to the ship.

The LPS is modified to pump water samples back to the ship for analysis with a suite of new, high-speed chemical systems. With this system, nutrient and carbonate chemistry fields can now be resolved with spatial resolutions approaching those attainable with in situ physical and bio-optical sensors.

During these brief surveys, we found physical variability on horizontal scales of $10-15 \mathrm{~km}$. We also found that spatial variability in chemical species occurs on similar scales, and that there are no simple correlations between physical, bio-optical and chemical parameters, which would alleviate the need to sample them all in high spatial resolution.

Figure $A$ shows some of the results obtained during the three-dimensional survey between $172^{\circ} \mathrm{E}$ and $174^{\circ} \mathrm{E}$. Warming of surface waters from above is evident from distributions of temperature, as are several intrusions of warmer modified circumpolar deep water at depths of 80-120 m in the western sections. Temperatures range from $-1.9^{\circ} \mathrm{C}$ to $-0.8^{\circ} \mathrm{C}$. The horizontal scale of variability is small; several prominent features appear to have north-south dimensions of only a few kilometers. East-west dimensions are also small, as seen by the lack of clear continuity between adjacent north-south track lines.
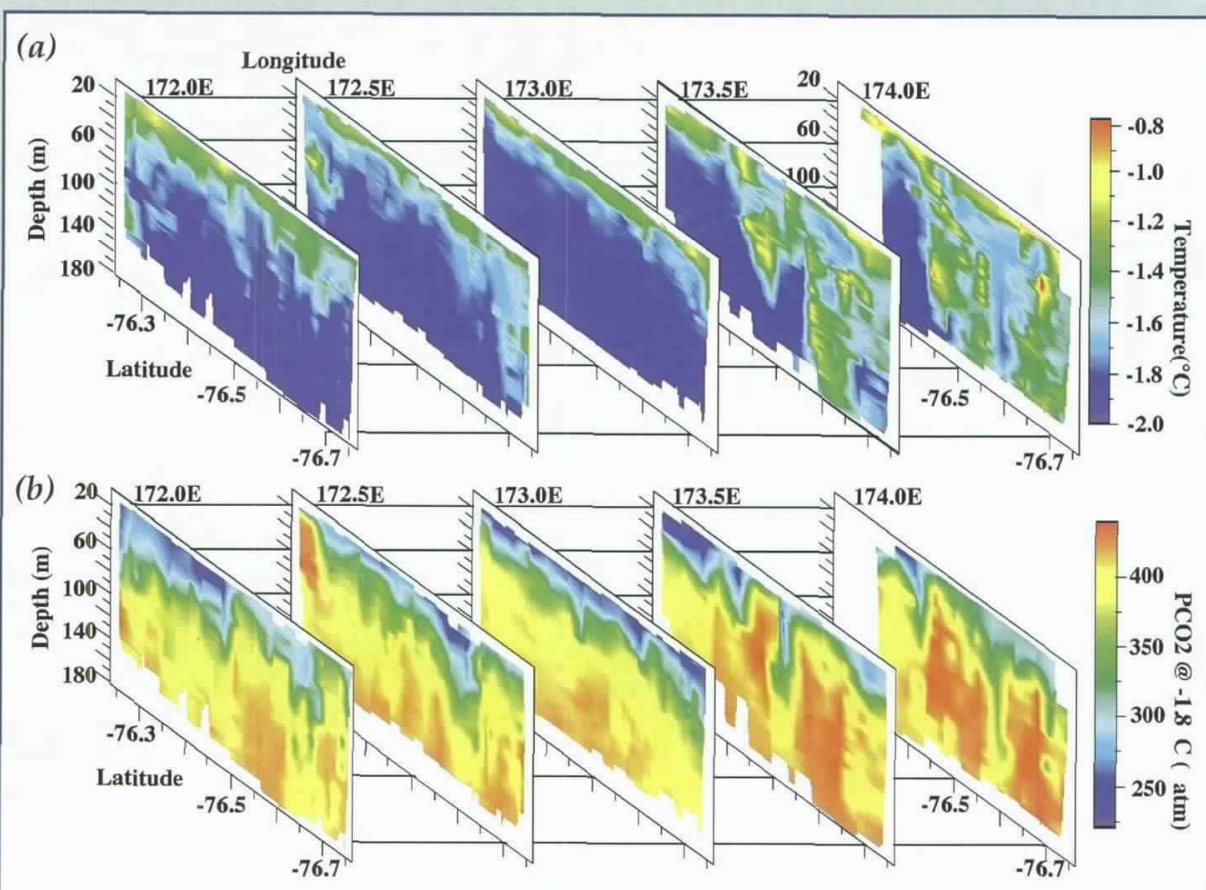

Figure A. Distributions of temperature (a) and $\mathrm{pCO}_{2}$ (b) in a $60 \mathrm{~km}^{2}$ grid in the Ross Sea, surveyed over a 20-hour period in December 1997 with the Lamont Pumping Seasoar (LPS). Temperature was measured with in situ sensors aboard the LPS; $\mathrm{PCO}_{2}$ was measured with a high-speed equilibration system aboard the ship in a sample seawater stream pumped back to the ship from the LPS. Both fields show patterns of modified circumpolar deep water at depth, identified as warm water with high $\mathrm{pCO}_{2}$ levels at depths of about $100 \mathrm{~m}$. At the surface, they show the effects of two different factors: warming from insolation, which elevates surface temperatures, and uptake of carbon during photoynthesis, which lowers surface $\mathrm{pCO}_{2}$. Both fields exhibit small horizontal scales of variability; many prominent features have horizontal dimensions of only about $10 \mathrm{~km}$.

The partial pressure of carbon dioxide $\left(\mathrm{pCO}_{2}\right)$, measured continuously at a frequency of $0.5 \mathrm{~Hz}$ in the sample stream delivered to the shipboard laboratory, shows the effects of water mass origin and biological productivity. The former was highest in the warm subsurface modified circumpolar deepwater, and the latter was lowest in areas of high chlorophyll and nitrate depletion. Unlike temperature, variability in $\mathrm{pCO}_{2}$ is large.

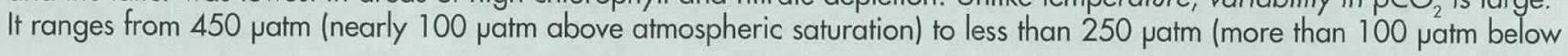


atmospheric saturation). As with temperature, this variability occurs over small horizontal scales, frequently $10 \mathrm{~km}$ or less.

Most of this variability would be missed by traditional hydrostation sampling. A quantitative analysis of the errors in predicting the true distributions of temperature and $\mathrm{pCO}_{2}$ by interpolation of coarse sampling indicates that resolution as fine as $15 \mathrm{~km}$ misses two-thirds of the total variability in well-resolved fields. While there are similarities in the apparent horizontal scale of $\mathrm{PCO}_{2}$ and temperature variability, one cannot be used as a proxy for the other. At greater depths, high temperatures and high $\mathrm{pCO}_{2}$ levels coincide; at the surface, low temperatures coincide with low $\mathrm{pCO}$. Therefore chemical fields that vary greatly in space cannot be simply estimated from well-resolved physical fields. Both must be measured with adequate resolution.

We are only beginning to speculate about the processes that could lead to such small horizontal-scale variability in the Ross Sea. The vertical stratification was weak in the study area. Thus narrow bands of surface waters that have experienced some warming or biological productivity could be mixed down to greater depths periodically, giving rise to some of the structure seen in Figure 1.

We do not know what causes such downward mixing. Winds were minimal during the two weeks over which the LPS surveys were carried out, and other surface phenomena, such as increased warming and sea-ice melting, should lead to enhanced stratification rather than downward convection. We also have no simple explanation as to why photosynthetic activity should be so variable in a region with abundant nutrients and light availability.

Further study is needed to unravel these relationships. We need to look with a keen eye at small horizontal-scale physical processes, using acoustic Doppler current profiler or microstructure-based measurements of physical transport, and phytoplankton physiology, employing optical measurements of photosynthetic efficiency and absorbance cross section or measurements of pigment distributions.

chemical models are maturing rapidly, as is their linking to observations through data assimilation (see Doney, this issue). If future research efforts are to develop a mechanistic understanding of ocean carbon cycling that is sound enough to facilitate skillful prediction, it will be essential to deal explicitly with the issues of physical-biogeochemical interactions at the scales on which these mechanisms operate. JGOFS experience suggests there is a great deal of biogeochemical activity associated with the internal weather of the sea.

\section{Acknowledgments}

The author gratefully acknowledges support from the National Science Foundation, the National Aeronautics and Space Administration and the Jet Propulsion Laboratory. Thanks go to Larry Anderson, David Archer, Bob Arnone, Jack Barth, Will Berelson, Ken Brink, Ken Buesseler, Fei Chai, Tommy Dickey, Gene Feldman, Marjy Friedrichs, Valery Kosnyrev, Craig Lee, Ricardo Letelier, Keith Moore, Sharon Smith, Colm Sweeney and Jim Yoder for contributing constructive critiques, ideas and figures to this effort. The author would like to thank the SeaWiFS Project and the Distributed Active Archive Center at Goddard Space Flight Center for production and distribution of the ocean color data used in this article. These activities are sponsored by NASA's Mission to Planet Earth.

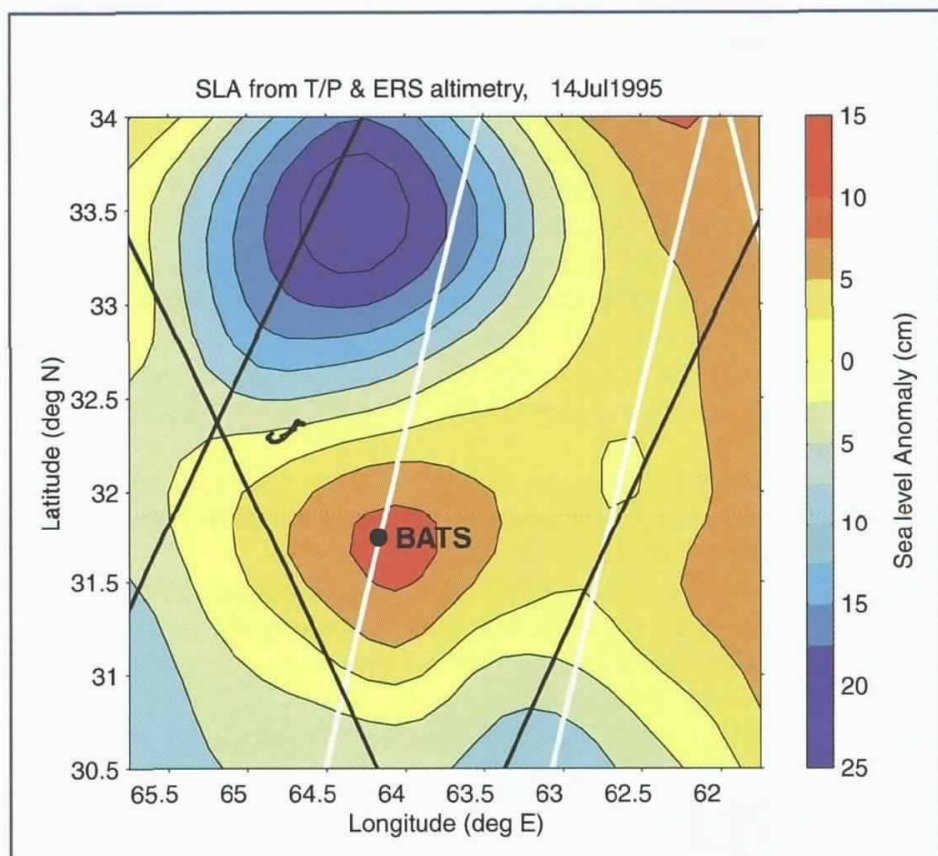

Figure 11. Objectively analyzed sea-level anomaly in the vicinity of the BATS site for July 14, 1995. Black and white lines show satellite ground tracks. The eddy feature observed in the Bermuda Testbed Mooring record in Figure 10 is clearly visible as a positive sea-level anomaly. 
Special thanks go to Anita Norton and Mardi Bowles for their help in preparation of the manuscript and editorial revision. This is WHOI contribution 10503 and U.S. JGOFS Contribution Number 671.

\section{See}

http://science.whoi.edu/users/mcgillic/papers/ tos-jgofs.pdf for a version of this paper that includes full references.

\section{References}

Archer, D., J. Aiken, W. Balch, R. Barber, J. Dunne, P. Flament, W. Gardner, C. Garside, C. Goyet, E. Johnson, D. Kirchman, M. McPhaden, J. Newton, E. Peltzer, L. Welling, J. White and J. Yoder, 1997: A meeting place of great ocean currents: shipboard observations of a convergent front at $2^{\circ} \mathrm{N}$ in the Pacific. Deep-Sea Res. II, 44, 1827-1849.

Barber, R., J. Marra, R. Bidigare, L. Codispoti, D. Halpern, Z. Johnson, M. Latasa, R. Goericke and S. Smith, 2001: Primary productivity and its regulation in the Arabian Sea during 1995. Deep-Sea Res. II, 48, 1127-1172.

Barth, J., T. Cowles and S. Pierce, 2001: Mesoscale physical and bio-optical structure of the Antarctic Polar Front near $170^{\circ} \mathrm{W}$ during austral spring. J. Geophys. Res., in press.

Bender, M., H. Ducklow, J. Kiddon, J. Marra and J. Martin, 1992: The carbon balance during the 1989 spring bloom in the North Atlantic Ocean, $47^{\circ} \mathrm{N}, 20^{\circ} \mathrm{W}$. Deep-Sea Res. 39, 1707-1725.

Bidigare, R. and M. Ondrusek, 1996: Spatial and temporal variability of phytoplankton pigment distributions in the central equatorial Pacific Ocean. Deep-Sea Res. II, 43, 809-833.

Brink, K., R. Arnone, P. Coble, C. Flagg, B. Jones, J. Kindle, C. Lee, D. Phinney, M. Wood, C. Yentsch and D. Young, 1998: Monsoons boost biological productivity in Arabian Sea. EOS, 79, 165, 168-169.

Chai, F., S. Lindley and R. Barber, 1996: Origin and maintenance of a high nitrate condition in the equatorial Pacific. Deep-Sea Res. II, 43, 1031-1064.

Dugdale, R. and F. Wilkerson, 1998: Silicate regulation of new production in the equatorial Pacific upwelling. Nature, $391,270-273$.

Friedrichs, M. and E. Hofmann, 2001: Physical control of biological processes in the central equatorial Pacific Ocean. Deep-Sea Res. I, 48, 1023-1069.

Honjo, S., J. Dymond, R. Collier and S. Manganini, 1995: Export production of particles to the interior of the equatorial Pacific Ocean during the 1992 EqPac experiment. Deep-Sea Res. II, 42, 831-870.

Honjo, S., J. Dymond, W. Prell and V. Ittekkot, 1999: Monsoon-controlled export fluxes to the interior of the Arabian Sea. Deep-Sea Res. II, 46, 1859-1902.

Honjo, S., R. Francois, S. Manganini, J. Dymond and R. Collier, 2000: Particle fluxes to the interior of the Southern Ocean in the Western Pacific sector along $170^{\circ}$ W. Deep-Sea Res. II, 47, 3521-3548.

Jenkins, W., 1988: The use of anthropogenic tritium and helium-3 to study subtropical gyre ventilation and circulation. Phil. Trans. Roy. Soc., 325, 43-61.

Jenkins, W. and J. Goldman, 1985: Seasonal oxygen cycling and primary production in the Sargasso Sea. J. Mar. Res., $43,465-491$.
Kim, H.-S., C. Flagg and S. Howden, 2001: Northern Arabian Sea variability from Topex/Poseidon altimetry data: an extension of the U.S. JGOFS/ONR shipboard ADCP study. Deep-Sea Res. II, 48, 1069-1096.

Latasa, M. and R. Bidigare, 1998: A comparison of phytoplankton populations of the Arabian Sea during the Spring Intermonsoon and Southwest Monsoon of 1995 as described by HPLC-analyzed pigments. Deep-Sea Res. II, 45, 2133-2170.

Lee, C., B. Jones, K. Brink and A. Fischer, 2000: The upperocean response to monsoonal forcing in the Arabian Sea: seasonal and spatial variability. Deep-Sea Res. II, 47, 1177-1226.

Letelier, R., D. Karl, M. Abbott, P. Flament, M. Freilich and R. Lukas, 2000: Role of late winter mesoscale events in the biogeochemical variability of the upper water column of the North Pacific Subtropical Gyre. J. Geophys. Res., 105, $28,723-28,739$.

McGillicuddy, D., A. Robinson and J. McCarthy, 1995: Coupled physical and biological modeling of the spring bloom in the North Atlantic (II): three dimensional bloom and post-bloom processes. Deep-Sea Res. I, 42, 1313-1398.

McGillicuddy, D., A. Robinson, D. Siegel, H. Jannasch, R. Johnson, T. Dickey, J. McNeil, A. Michaels and A. Knap, 1998: Influence of mesoscale eddies on new production in the Sargasso Sea. Nature, 394, 263-265.

McNeil, J., H Jannasch, T. Dickey, D. McGillicuddy, M. Brzezinski and C. Sakamoto, 1999: New chemical, biooptical and physical observations of upper ocean response to the passage of a mesoscale eddy off Bermuda. J. Geopitys. Res., 104, 15, 537-15, 548.

Moore, K. and M. Abbott, 2000: Phytoplankton chlorophyll distributions and primary production in the Southern Ocean. J. Geophys. Res., 105, 28, 709-28, 722.

Murray, J., R. Barber, M. Roman, M. Bacon and R. Feely, 1994: Physical and biological controls on carbon cycling in the Equatorial Pacific. Science, 266, 58-65.

Newton, P., R. Lampitt, T. Jickells, P. King and C. Boutle, 1994: Temporal and spatial variability of biogenic particle fluxes during the JGOFS northeast Atlantic process studies at $47^{\circ} \mathrm{N}, 20^{\circ} \mathrm{W}$. Deep-Sea Res. I, 41, 1617-1642.

Robinson, A., D. McGillicuddy, J. Calman, H. Ducklow, M. Fasham, F. Hoge, W. Leslie, J. McCarthy, S. Podewski, D. Porter, G. Saure and J. Yoder, 1993: Mesoscale and upper ocean variabilities during the 1989 JGOFS bloom study. Deep-Sea Res. II, 40, 9-35.

Sarmiento, J., T. Hughes, R. Stouffer and S. Manabe, 1998: Simulated response of the ocean carbon cycle to anthropogenic climate warming. Nature, 393, 245-249.

Siegel, D.A., and D.J. McGillicuddy and E.A. Fields, 1999: Mesoscale eddies, satellite altimetry and new production in the Sargasso Sea. J. Geophys. Res., 104(C6), 13, 359-13, 379.

Smith, S., 2001: Understanding the Arabian Sea: reflections on the 1994-1996 Arabian Sea expedition. Deep-Sea Res. II, 48, 1385-1402.

Smith, W., R. Anderson, J. Moore, L. Codispoti and J. Morrison, 2000. The U.S. Southern Ocean Joint Global Ocean Flux Study: an introduction to AESOPS. Deep-Sea Res. II, 47, 3073-3093.

Woods, J., 1988: Mesoscale upwelling and primary production. In: Toward a Theory on Biological-Physical Interactions in the World Ocean. B. Rothschild, ed. D. Reidel, Dordrecht.

Yoder, J., S. Ackleson, R. Barber, P. Flament and W. Balch, 1994: A line in the sea. Nature, 371, 689-692 